\title{
基 \\ Plasma rico em plaquetas: mecanismo de ação, produção e indicações de uso - Revisão de literatura
}

[Platelet-rich plasma: mechanisms of action, production and indications for use a review]

\section{"Revisão/Review"}

\author{
Grazielle Anahy de Sousa Aleixo*, Maria Cristina de Oliveira Cardoso Coelho, \\ Sabrina Cândido Trajano, Lilian Sabrina Silvestre de Andrade
}

Departamento de Medicina Veterinária, Universidade Federal Rural de Pernambuco, Recife-PE, Brasil.

*Autor para correspondência/Corresponding author: E-mail: grazielle@yahoo.com

\section{Resumo}

O plasma rico em plaquetas (PRP) é um produto biológico produzido a partir de um processo de centrifugação de sangue autólogo, permitindo a extração de um plasma com uma concentração de três a cinco vezes maior de plaquetas em relação a sua quantidade no sangue basal. Muitas pesquisas desenvolvidas nas mais diversas áreas da Medicina, especialmente em odontologia, ortopedia e cirurgia reconstrutiva têm sugerido que o produto potencializa o processo de cicatrização tecidual no local aonde o mesmo é aplicado, por meio da liberação de mediadores biológicos denominados fatores de crescimento. Acredita-se que os fatores de crescimento, entre eles o fator de crescimento derivado das plaquetas, fator de crescimento transformador $\beta$, fator de crescimento epitelial e fator de crescimento vascular endotelial, sejam capazes de estimular vários processos biológicos envolvidos na recuperação tecidual como a mitose, diferenciação celular, quimiotaxia, síntese de matriz e angiogênese. Diante das informações descritas, e com o intuito de divulgar e difundir o uso do PRP na medicina veterinária, tendo em vista que seu emprego ainda não é uma prática comum, objetivou-se realizar uma revisão de literatura sobre o produto, descrevendo sobre a sua ação no tecido alvo, indicações de uso, processo de produção e os resultados obtidos em alguns estudos já realizados.

Palavras-Chave: Concentrado de plaquetas; fatores de crescimento; recuperação tecidual.

\begin{abstract}
Platelet rich plasma (PRP) is a biological product produced by centrifugation of autologous blood, allowing the extraction of plasma with a platelets concentration three to five times higher, compared to their amount in basal blood. Many research's developed in several areas of medicine, especially in dentistry, orthopedics and reconstructive surgery, have suggested that the product enhances the tissue healing process in the wound where it is applied, through the release of biological mediators called growth factors. It is believed that the growth factors, including platelet-derived growth factor, transforming growth factor $\beta$, epidermal growth factor and vascular endothelial growth factor, are capable of stimulating multiple biological processes involved in tissue recovery such as mitosis, cell differentiation, chemotaxis, matrix synthesis and angiogenesis. Based on the described information, and aiming to promote the use of PRP in veterinary medicine, associated to the fact that its application isn't a common practice, this paper aimed to conduct a literature review about the product, describing its action in tissue, indications for use, production and some results of previous studies.
\end{abstract}

Keywords: platelets concentration; growth factors; tissue recovery.

\section{Introdução}

O Plasma Rico em Plaquetas (PRP) é um produto obtido pela centrifugação do sangue do próprio paciente, objetivando concentrar uma maior quantidade de plaquetas em um menor 
volume de plasma. Ele é capaz de concentrar em três a cinco vezes a quantidade de plaquetas em comparação ao sangue basal (Whitlow et al., 2008).

O uso desse produto para auxiliar na cicatrização de tecidos tem sido objeto de estudo e bastante reportado na literatura médica (Floryan e Berghoff, 2004) e atualmente, tem-se dado muita ênfase ao uso do PRP em diversas áreas médicas, principalmente, em odontologia e ortopedia.

Estudos desenvolvidos nas mais diversas áreas têm sugerido que o produto potencializa $o$ processo de cicatrização tecidual, por meio da liberação de mediadores biológicos denominados fatores de crescimento (FC's) no local da sua aplicação. Os principais FC's envolvidos na recuperação tecidual que comprovadamente estão presentes nas plaquetas são o fator de crescimento derivado das plaquetas (PDGF), fator de crescimento transformador $\beta$ (TGFß), fator de crescimento vascular endotelial (VEGF) e fator de crescimento epitelial (EGF) (Marx, 2004). Alguns autores também citam como sendo importante o fator de crescimento fibroblástico (FGF) e o fator de crescimento semelhante à insulina (IGF) (Moreira et al., 2008).

Acredita-se que os FC's sejam capazes de estimular vários processos envolvidos na recuperação tecidual por promoverem a quimiotaxia, proliferação e diferenciação celular, modulação imunológica e ainda apresentarem atividade antimicrobiana (Bolta, 2007).

Baseado nas informações descritas, este trabalho de revisão tem como objetivo realizar uma ampla descrição sobre o PRP e seu uso na reparação tecidual, descrevendo sobre os diferentes métodos para a obtenção do mesmo e as qualidades atribuídas ao produto.

\section{Plasma rico em plaquetas: definição e modo de ação}

Entende-se por PRP, um produto obtido pela centrifugação de sangue autógeno, que resulta em uma maior concentração de plaquetas em um menor volume de plasma (Vendramin et al., 2006; Pagliosa e Alves, 2007). De acordo com Marx (2004), o incremento na plaquetometria do PRP deve ser de quatro a cinco vezes com relação ao valor encontrado no sangue basal.

O PRP também recebe outras denominações tais como plasma enriquecido com plaquetas, plasma rico em fatores de crescimento, concentrado de plaquetas ou plasma autógeno de plaquetas (Feres Junior et al., 2004).

Inicialmente o PRP foi desenvolvido com o objetivo de reduzir as hemorragias durante procedimentos cirúrgicos (Nunes Filho et al., 2007), entretanto, seu uso começou a se tornar popular na odontologia humana, mais especificamente em cirurgias orais e maxilofaciais, a partir de 1998 com a publicação de artigos relatando que a associação do PRP a enxertos de osso autógeno potencializava o processo de reparação óssea (Albuquerque et al., 2008). A partir de então, o produto passou a ser usado com sucesso em cirurgia ortopédica, cardíaca, plástica (Whitlow et al., 2008), geral, vascular, neurológica, obstétrica, ginecológica e oftálmica (Floryan e Berghoff, 2004).

O principal intuito de obter uma maior quantidade de plaquetas é devido a existência de pelo menos 60 substâncias biologicamente ativas em seu interior, que participam dos mecanismos de reparação tecidual (Bolta, 2007). Entretanto, para que essas substâncias sejam liberadas e possam agir, as plaquetas precisam ser ativadas por um fator agonista (Jain, 1993). Após a ativação das plaquetas, elas mudam de formato e passam a apresentar projeções membranosas longas conhecidas como pseudópodos e os grânulos localizados no seu interior, são rompidos levando a liberação do seu conteúdo (Jain, 1993; Hoffbrand et al., 2004).

Os mediadores biológicos secretados pelos grânulos plaquetários após a ativação das plaquetas são a trombina, tromboxano A2, adenosina difosfato, tromboplastina, fatores de coagulação, cálcio, serotonina, histamina (Dark et al., 2005), fator de Von Willebrand, fibrinogênio (Whitlow et al., 2008), catecolaminas (López et al., 2007) e os fatores de crescimento (FC's), sendo estes últimos os mais importantes (Bolta, 2007) pelo fato deles serem capazes de estimular diferentes processos celulares, tais como a mitogênese, síntese de matriz (Barbosa et al., 2008) quimiotaxia, diferenciação, metabolismo e angiogênese (Floryan e Berghoff, 2004; Barroso et al., 2007; Maia e Souza, 2009).

Os FC's envolvidos na recuperação tecidual e que comprovadamente são produzidos por plaquetas são o fator de crescimento derivado das plaquetas (PDGF), fator de crescimento transformador beta (TGF $\beta$ ), fator de crescimento vascular endotelial (VEGF), fator de crescimento epitelial (EGF) (Marx, 2004; Roukis et al., 2006), 
fator de crescimento fibroblástico (FGF) e fator de crescimento semelhante a insulina (IGF) (Bolta, 2007; Moreira et al., 2008).

A ação dos diferentes FC's são bem similares (Tabela 1), entretanto, sabe-se que nenhum deles por si só é capaz de restaurar uma lesão isoladamente (Dark et al., 2005) e que na realidade eles atuam em sinergismo no local da lesão (Bolta, 2007).

Tabela 1. Fatores de crescimento e suas principais funções.

\begin{tabular}{ll}
\hline \multicolumn{1}{c}{ Fatores de Crescimento (FC's) } & \multicolumn{1}{c}{ Principais funções } \\
\hline Transformador beta (TGFß) & Quimiotaxia, diferenciação celular e angiogênese. \\
Derivado da plaqueta (PDGF) & Angiogênese, quimiotaxia, mitogênese e formação de colágeno. \\
Fibroblástico (FGF) & $\begin{array}{l}\text { Diferenciação de osteoblastos, proliferação de fibroblastos, angiogênese, } \\
\text { mitogênese e quimiotaxia. }\end{array}$ \\
Similar a insulina (IGF) & Mitogênese e diferenciação de células mesenquimais. \\
Vascular endotelial (VEGF) & Quimiotaxia e proliferação de células endoteliais e aumento da \\
& permeabilidade vascular. \\
Epitelial ou epidermal (EGF) & Mitogênese, atividade migratória e diferenciação de células epiteliais, \\
& fibroblastos, células renais e da glia. \\
\hline
\end{tabular}

Fonte: Martínez-González et al. (2002).

\section{Produção do PRP}

Atualmente, o PRP é considerado um produto de fácil obtenção e baixo custo (Maia e Souza, 2009), entretanto no início sua produção era mais complexa e tinha um custo bastante elevado. Nas primeiras tentativas, eram utilizados grandes equipamentos de autotransfusão que separavam o plasma das hemácias, porém era preciso colher amostras de sangue volumosas (aproximadamente $450 \mathrm{~mL}$ ) (Jameson, 2007) além da presença de um profissional experiente para realizar tal procedimento e manusear a máquina (Vendramin et al., 2006). Como o sangue era colhido de um cateter venoso profundo posicionado no paciente durante a cirurgia, o procedimento só podia ser realizado dentro de ambiente cirúrgico e com o paciente anestesiado, o que resultava em maior risco de morbidade (De Rossi et al., 2009).

Com o passar dos anos foram sendo criados equipamentos automáticos mais compactos e simples como o AG Curasan ${ }^{\circledR}, \quad 3 \mathrm{i}$ PCCS $^{\circledR}$, Sequire $^{\circledR}$, SmartPReP $^{\circledR}$ (Kevy e Jacobson, 2004) Magellan ${ }^{\circledR}$, AutoloGel System ${ }^{\circledR}$, Autologous Growth Factor ${ }^{\circledR}$, Gravitational Platelet Separation II System ${ }^{\circledR}$, Symphony II Platelet Concentrate System $^{\circledR}$ e Accelerate Platelet-Rich Plasma Gel ${ }^{\circledR}$ (Roukis et al., 2006). Apesar de exigirem menores amostras de sangue, esses aparelhos apresentam custo bastante elevado, limitando o seu uso (Kevy e Jacobson, 2004).

Visando facilitar e reduzir ainda mais as despesas de produção do PRP, outros protocolos usando centrífugas laboratoriais comuns foram criados e testados por diversos pesquisadores como Ferraz et al. (2007), Barbosa et al. (2008) e Aleixo et al. (2011).

No trabalho realizado por Aleixo et al. (2011), a área da colheita tinha os pelos removidos com uma lâmina de tricotomia e era higienizada com solução de álcool a $70 \%$. Realizava-se a venopunção da veia cefálica ou safena usando um sistema de colheita a vácuo e frascos de 4,5 mL contendo citrato de sódio como anticoagulante. Segundo Gentry (2006), o citrato de sódio é o anticoagulante recomendado para produção do PRP porque ele se liga aos íons de cálcio formando quelatos, impedindo que ocorra a coagulação do plasma, entretanto, posteriormente, se for adicionado cloreto de cálcio para produção do gel de plaquetas, o coágulo é formado naturalmente.

Com relação ao processo de centrifugação, etapa essencial para a fabricação do PRP (Pagliosa e Alves, 2007), a mesma pode ser realizada em um único momento ou em duas etapas, dependendo do protocolo empregado (Martínez-González et al., 2002; Pagliosa e Alves, 2007) (Tabela 2).

Levando em consideração a variação das densidades, após a centrifugação de uma amostra de sangue, as hemácias, que tem maior peso, tendem a se depositar no fundo do tubo, enquanto que os leucócitos se localizam em uma zona intermediária, e o plasma fica no alto (Roukis et al., 2006). A junção das plaquetas e leucócitos corresponde a uma camada esbranquiçada chamada de zona de névoa (Jain, 1993) (Figura 1). 


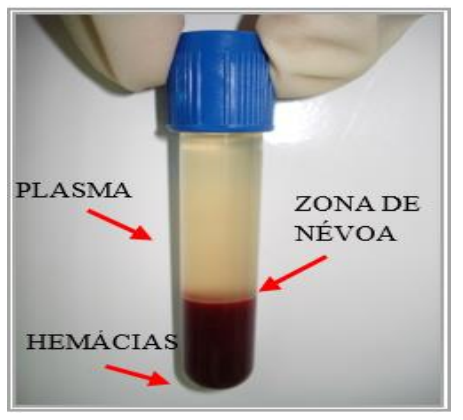

Figura 1. Plasma, zona de névoa e hemácias separadas após a primeira centrifugação.
Em protocolos de centrifugação dupla, após o descarte das hemácias o plasma retorna para a centrífuga (Jameson, 2007) levando a precipitação das plaquetas e das poucas hemácias (que porventura possam estar presentes) no fundo do tubo (Vendramin et al., 2006). Posteriormente, $80 \%$ da parte superior do plasma, correspondente ao plasma pobre em plaquetas (PPP) é descartado e o botão plaquetário localizado no fundo do frasco é ressuspendido no restante do plasma dando origem ao PRP (Barroso et al., 2007).

Tabela 2. Alguns protocolos utilizados para produção do PRP em centrífuga laboratorial.

\begin{tabular}{|c|c|c|c|}
\hline Referência & Protocolo & Material utilizado & Volume de sangue \\
\hline $\begin{array}{l}\text { Feres Junior et al. } \\
(2004)\end{array}$ & $\begin{array}{l}\text { Única centrifugação: } 1400 \mathrm{rpm} / 10 \\
\text { minutos }\end{array}$ & $\begin{array}{l}4 \text { frascos de } 5 \mathrm{~mL} \\
\text { Centrífuga Fanem }\end{array}$ & $20 \mathrm{~mL}$ \\
\hline Ferraz et al. (2007) & $\begin{array}{l}1^{\text {a }} \text { centrifugação: } 800 \mathrm{rpm} / 10 \text { minutos } \\
2^{\text {a }} \text { centrifugação: } 1600 \mathrm{rpm} / 10 \text { minutos }\end{array}$ & $\begin{array}{l}\text { Frascos de } 10 \mathrm{~mL} \\
\text { Centrífuga }\end{array}$ & $40 \mathrm{~mL}$ \\
\hline Barbosa et al. (2008) & $\begin{array}{l}1^{a} \text { centrifugação: } 1300 \mathrm{rpm} / 8 \text { minutos } \\
2^{\text {a }} \text { centrifugação: } 1300 \mathrm{rpm} / 8 \text { minutos }\end{array}$ & $\begin{array}{l}4 \text { tubos de } 4,5 \mathrm{~mL} \\
\text { Centrífuga }\end{array}$ & $18 \mathrm{~mL}$ \\
\hline De Rossi et al. (2009) & $\begin{array}{l}1^{\mathrm{a}} \text { centrifugação: } 300 \mathrm{~g} / 10 \text { minutos } \\
2^{\mathrm{a}} \text { centrifugação: } 640 \mathrm{~g} / 10 \text { minutos }\end{array}$ & $\begin{array}{l}2 \text { tubos de } 10 \mathrm{~mL} \\
\text { Centrífuga Sigma }\end{array}$ & $20 \mathrm{~mL}$ \\
\hline Messora et al. (2009) & Centrifugação única: $160 \mathrm{~g} / 6$ minutos & $\begin{array}{l}\text { Tubos } \\
\text { Centrífuga Beckman }\end{array}$ & $10 \mathrm{~mL}$ \\
\hline Silva et al. (2009) & $\begin{array}{l}1^{\mathrm{a}} \text { centrifugação: } 1300 \mathrm{rpm} / 12 \text { minutos } \\
2^{\mathrm{a}} \text { centrifugação: } 1300 \mathrm{rpm} / 8 \text { minutos }\end{array}$ & $\begin{array}{l}2 \text { tubos de } 4,5 \mathrm{~mL} \\
\text { Centrífuga }\end{array}$ & $9 \mathrm{~mL}$ \\
\hline $\begin{array}{l}\text { Vendruscolo et al. } \\
(2012)\end{array}$ & $\begin{array}{l}1^{\mathrm{a}} \text { centrifugação: } 90 \mathrm{~g} / 10 \text { minutos } \\
2^{\mathrm{a}} \text { centrifugação: } 180 \mathrm{~g} / 10 \text { minutos }\end{array}$ & $\begin{array}{l}\text { Tubos com citrato de } \\
\text { sódio a } 3,2 \% \\
\text { Centrífuga }\end{array}$ & $27 \mathrm{~mL}$ \\
\hline
\end{tabular}

O processo de centrifugação deve ser executado com muita precisão para separar as plaquetas das células vermelhas e obter um plasma com altas concentrações de plaquetas íntegras (Marx, 2004), pois a sua fragmentação e liberação precoce dos FC's na solução reduz a função e eficácia do PRP (Adler e Kent, 2002).

Quando a colheita de sangue transcorre sem problemas e o método empregado é adequado, as plaquetas intactas e viáveis ficam prontas para liberar os FC's após sua ativação (Jameson, 2007). Ao ativar o PRP, em 10 minutos e na primeira hora, $70 \%$ e $100 \%$ dos FC's já foram liberados, respectivamente (Marx, 2001).

São fatores agonistas indicados para ativar o PRP, a trombina bovina (Roukis et al., 2006; Pagliosa e Alves, 2007), tromboplastina ou a trombina autógena (Barbosa et al., 2008). Já foi citado também o uso de outras substâncias, tais como o batroxobin (produto isolado do veneno de serpentes) (Bolta, 2007).
A partir desse momento, o produto adquire uma consistência gelatinosa (Albuquerque et al., 2008), que facilita a sua aplicação no local desejado (Vendramin et al., 2006) (Figura 2). A mistura pode ser aplicada diretamente sobre a lesão ou incisão cirúrgica ou previamente misturado com enxertos ósseos e só então aplicado ao leito receptor (Jameson, 2007).

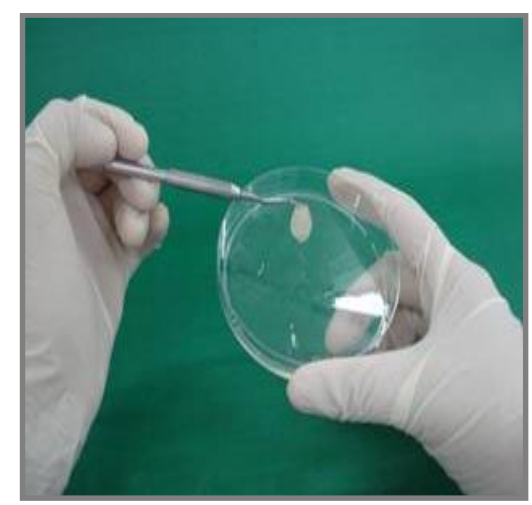

Figura 2. Gel de PRP formado após a adição de um fator ativador. 
Após sua produção, o PRP deve apresentar uma concentração em torno de 1.000 .000 de plaquetas/ $\mu \mathrm{L}$ (Marx, 2004; Suaid et al., 2007; Barbosa et al., 2008). De acordo com Eurides et al. (2015), concentrações superiores a 300.000 plaquetas $\mu \mathrm{L}-1$ no sangue basal são suficientes para o preparo do PRP.

\section{Indicações de uso do PRP}

As aplicações clínicas do PRP são diversas e muitos dos benefícios citados com relação ao seu uso são aplicáveis para as cirurgias de pele (Adler e Kent, 2002), tendo sido relatado o seu emprego em operações plásticas e procedimentos reconstrutivos em seres humanos (Jameson, 2007; Sommeling et al., 2013).

Usando o PRP em flapes cutâneos, Man et al. (2001), citaram que o mesmo foi capaz de auxiliar no processo de hemostasia e estimular a formação de novos vasos sanguíneos, o que por sua vez, reduziu as complicações pós-operatórias (ex. hematoma, seroma e isquemia), potencializou a cicatrização e diminuiu o tempo de recuperação cirúrgica. Sánchez et al. (2003), também atribuíram ao produto uma revascularização e reepitelização mais intensa em flapes.

O PRP também tem sido empregado em cirurgias osteoarticulares, como no reparo de tendões, osteoartrite e fraturas (Vendramin et al., 2010; Carmona et al., 2011; Malhotra et al., 2012; Yamada et al., 2012). Resultados da associação do PRP com enxertos ósseos demostraram uma consolidação mais rápida e uma mineralização do enxerto em $50 \%$ do tempo requerido, além de aumentar em 15 a $30 \%$ a densidade do osso trabecular (Marx et al., 1998).

Seu uso também tem sido empregado no tratamento de lesões em ligamentos e tendões em equinos, apresentando resultados positivos (Rindermann et al., 2010; Torricelli et al., 2011; Machado et al., 2015). Messora et al. (2009) utilizaram o produto na cicatrização de defeitos mandibulares de cães tratados com enxerto ósseo alógeno. Em cães sua aplicação vem aumentando em fraturas de ossos longos associados ou não a enxertos (Souza et al., 2011; Lenza et al., 2013).

$\mathrm{Na}$ área de oftalmologia, mais especificamente no tratamento de úlcera de córnea em cães, o PRP na forma de colírio ou de tampão sólido demonstrou ser um excelente adjuvante, diminuindo o processo inflamatório, a dor e contribuindo com a cicatrização epitelial (Donatti et al., 2013; Merlini et al., 2014).

Apesar de todos os trabalhos citados, de acordo com Maia e Souza (2009) poucos são os experimentos relacionados ao emprego do PRP na Medicina Veterinária, o que justifica o desenvolvimento de mais experimentos com animais domésticos e silvestres.

\section{Considerações finais}

O plasma rico em plaquetas é um produto autógeno de fácil obtenção que tem demonstrado grande potencial para auxiliar na reparação de lesões teciduais, através da ação de fatores de crescimentos presentes no interior das plaquetas. Diante das diversas possibilidades de uso do PRP e baseado nos resultados animadores alcançados em terapia de lesões oculares, ósseas, cutâneas e tendínea, espera-se que esse trabalho de revisão contribua para a maior difusão do seu uso, especialmente na medicina veterinária.

\section{Referências}

Adler, S.C.; Kent, K.J. Enhancing wound healing with growth factors. Facial Plastic Surgery Clinics of North America, 10: 129-146, 2002.

Albuquerque, D.P.; Oliveira, T.M.F.; Maranhão Filho, A.W.A.; Milhomens Filho, J.A.; Gusmão, E.S. Aplicação clínico-cirúrgica do plasma rico em plaquetas - estudo revisional. Odontologia Clinico Cientifica, 7(2): 119122, 2008.

Aleixo, G.A.S.; Coelho, M.C.O.C.; Teixeira, M.N.; Mesquita, E.P.; Oliveira, F.F.; Zubieta, L.M.V.; Almeida, T.L.C.; Guimarães, A.L.N.; Maia, F.C.; Zacarias, T.F.L.; Santos, S.M. L.G.; Lima, C.P.S. Comparação entre dois métodos para obtenção do plasma rico em plaquetas, em cães. Arquivo Brasileiro de Medicina Veterinária e Zootecnia, 63(3): 567-573, 2011.

Barbosa, A.L.T.; Del Carlo, R.J.; Gomes, H.C.; Oliveira, A.C.; Monteiro, B.S.; Del Carlo, B.N. Plasma rico em plaquetas para reparação de falhas ósseas em cães. Ciência Rural, 38(5): 1335-1340, 2008.

Barroso, C.S.T.; Benito, J.C.; Puig, A.G. Calidad del plasma rico em plaquetas: estúdio de la activación plaquetaria. Revista Española de Cirugía Oral y Maxilofacial, 29(4): 240248, 2007. 
Bolta, P.R.Z. Use of platelet growth factors in treating wounds and soft-tissue injuries. Acta Dermatovenerol APA, 16(4): 156-165, 2007.

Carmona, J.U.; Lopez, C.; Giraldo, C.E. Uso de concentrados autólogos de plaquetas como terapia regenerativa de enfermedades crónicas del aparato musculoesquelético equino. Archivos de Medicina Veterinária, 43:1-10, 2011.

De Rossi, R.; Coelho, A.C.A.O.; Mello, G.S.; Frazílio, F.O.; Leal, C.R.B.; Facco, G.G.; Brum, K.B. Effects of platelet-rich plasma gel on skin healing in surgical wound in horses. Acta Cirúrgica Brasileira, 24(4): 276-281, 2009.

Donatti, C.; Brandão, C.V.S; Ranzani, J.J.T.; Perches, C.S.; Padovani, C.R.; Pellizzon, C. H.; Sereno, M.G. Uso de plasma rico em plaquetas no reparo de úlceras de córnea profundas induzidas em coelhos. Avaliação clínica e histomorfométrica. Arquivo Brasileiro de Medicina Veterinária e Zootecnia, 65(3): 809-818, 2013.

Eurides, D.; Guimarães, C.P.A.; Beletti, M.E.; Mundim, A.V.; Souza, L.A.; Gonçalves, G. F.; Eurides, G.P. Plasma rico em plaquetas autólogas na cicatrização do tendão do músculo gastrocnêmio de coelhos. Brazilian Journal Veterinary Research and Animal Science, 52(1): 48-56, 2015.

Feres Junior, F.; Passanezi, E.; Greghi, S.L.A.; Passanezi, A. Análise comparativa do índice de sucesso dos implantes osteointegrados com e sem a utilização de prp, no protocolo de fixação. Semina: Ciências Biológicas e da Saúde, 25: 9-21, 2004.

Ferraz, V.C.M.; Ferrigno, C.R.A.; Schmaedecke, A. Platelet concentration of platelet rich plasma from dogs, obtained through three centrifugation speeds. Brazilian Journal Veterinary Research and Animal Science, 44(6): 435-440, 2007.

Floryan, K.M.; Berghoff, W.J. Intraoperative use of autologous plateletrich and platelet-poor plasma for orthopedic surgery patients. AORN Journal, 80(4): 668-674, 2004.

Gentry, P.A. Coagulação sanguínea e hemostasia. In: Reece, W. O. Dukes/Fisiologia dos Animais Domésticos. 12. ed. Rio de Janeiro: Guanabara Koogan, 2006. Cap.4, p.49-64.
Hoffbrand, A.V.; Pettit, J.E.; Moss, P.A.H. Plaquetas, coagulação do sangue $\mathrm{e}$ hemostasia. In: Fundamentos em hematologia. 4. ed. Porto Alegre: Artmed, 2004. Cap.18, p.244-257.

Jain, N.C. Essentials of veterinary hematology. Philadelphia: Lea \& Febiger, 1993. Cap.1, p.1- 18 .

Jameson, C.A. Autologous platelet concentrate for the production of platelet gel. Labmedicine, 38(1): 39- 42, 2007.

Kevy, S.V.; Jacobson, M.S. Comparison of methods for point of care preparation of autologous platelet gel. Journal of the American Society of Extra-Corporeal Technology, 36: 28-35, 2004.

Lenza, M.; Ferraz, S. B.; Lenza, M.; Ferraz, S.B. Viola, D.C.M.; Santos, O.F.P.; Neto, M.C. Ferretti, M. Plasma rico em plaquetas para consolidação de ossos longos. Einstein, 11(1):122-127, 2013.

López, J.L.; Chimenos, E.; Sanchez, J.M.; Castañeda, P. Plasma rico en factores de crecimiento y regeneración ósea. Dentum, 7(3): 108-112, 2007.

Machado, E.C.; Campebell, R.C. Tendinite do Flexor digital superficial em equinos: Tratamento com plasma rico em plaquetas. REVET - Revista Científica de Medicina Veterinária, 2(1): 15-29, 2015.

Maia, L.; Souza, M.V. Componentes ricos em plaquetas na reparação de afecções tendoligamentosas e osteoarticulares em animais. Ciência Rural, 39(4): 1267-1274, 2009.

Malhotra, A.; Pelletier, M.H.; Yu, Y.; Walsh, W. R. Can platelet-rich plasma improve bone healing? A comparison between the theory and experimental outcomes. Archives of Orthopaedic and Trauma Surgery, 33: 153-165, 2012.

Man D.; Plosker, H.; Winland-Brown, J.E. The use of autologous platelet-rich plasma (platelet gel) and autologous platelet-poor plasma (fibrin glue) in cosmetic surgery. Plastic and Reconstructive Surgery, 107: 229-237, 2001.

Martínez-González, J.M.; Sánchez, J.C.; Lafuente, J.C.G.; Trapero, J.C.; Gómez, G.C.E.; Lestón, J.M.S. Do ambulatory-use PlateletRich Plasma (PRP) concentrates present risks? Medicina Oral, 7(5): 383-390, 2002. 
Marx, R.E. Platelet-rich plasma: evidence to support its use. Journal of Oral Maxillofacial Surgery, 62: 489-496, 2004.

Marx, R.E.; Carlson, E.R.; Eichstaedt, R.M.; Schimmele, S.R.; Strauss, J.E.; Georgeff, K.R. Platelet-rich plasm: growth factor enhancement for bone grafts. Oral Surgery, Oral Medicine, Oral Pathology, 85(6): 638646, 1998.

Merlini, N.B.; Fonzar, J.F.; Perches, C.S.; Sereno, M.G.; Souza, V.L.; Estanislau, C.A.; Rodas, N.R.; Ranzani, J.J.T.; Maia, L.; Padovani, C.R.; Brandão, C.V.S. Uso de plasma rico em plaquetas em úlceras de córnea em cães. Arquivo Brasileiro de Medicina Veterinária e Zootecnia, 66(6): 1742-1750, 2014.

Messora, M.E.; Nagata, M.J.H.; Melo, L.G.N.; Furlaneto, F.A.C.; Deliberador, T.M.; Garcia, V.G.; Bosco, A.F. Análise de um protocolo de única centrifugação para o preparo do plasma rico em plaquetas (PRP) - estudo em coelhos. Revista Sul-Brasileira de Odontologia, 6(2): 135-141, 2009.

Moreira, D.C.; Sadigursky, M.; Reis, S.R.A.; Andrade, M.G.S. Fatores de crescimento plaquetários. Revisión de literatura. Revista Venezolana de Investigación Odontológica, 8(1): 14-25, 2008.

Nunes Filho, D.P.; Luppino, F.; Yaedú, R.Y.F.; Carvalho, P.S.P. Avaliação microscópica da ação do osso autógeno associado ou não ao PRP em cavidades ósseas de cães. Revista Implantnews, 4(3): 263-269, 2007.

Pagliosa, G.M.; Alves, G.E.S. Considerações sobre a obtenção e o uso do plasma rico em plaquetas e das células mesenquimais indiferenciadas em enxertos ósseos. Ciência Rural, 37(4): 1202-1205, 2007.

Rindermann, G.; Cislakova, M.; Arndt, G. Autologous conditioned plasma as therapy of tendon and ligament lesions in seven horses. Journal of Veterinary Science, 11(2): 173$175,2010$.

Roukis, T.S.; Zgonis, T.; Tiernan, B. Autologous platelet-rich plasma for wound and osseous healing: A review of the literature and commercially available products. Advances in Therapy, 23(2): 218-237, 2006.

Sánchez, A.R.; Sheridan, P.J.; Kupp, L.I. Is Platelet-rich plasma the perfect enhancement factor? A current review. International
Journal of Oral \& Maxillofacial Implants, 18: 93-103, 2003.

Silva, P.S.A.; Del Carlo, R.J.; Serakides, R.; Monteiro, B.S.; Balbinot, P.Z.; Eleoterio,

R.B.; Paez, O.L.A.; Viloria, M.I.V. Plasma rico em plaquetas associado ou não ao osso esponjoso autógeno no reparo de falhas ósseas experimentais. Ciência Rural, 39(1): 129-134, 2009.

Sommeling, C.E; Heyneman, A; Hoeksema, H.; Verbelen, J.; Stillaert, F.B; Monstrey, S. The use of platelet rich plasma in plastic surgery: A systematic review. Journal of Plastic Reconstuctive and Aesthetic Surgery, 66: 301-312, 2013.

Souza, T.F.B.; Ferreira, G.T.N.M.; Sakamoto, S. S.; Albuquerque, V.B.; Bomfim, S.R.M.; Andrade, A.L.D. Aspectos radiográficos e densitométricos de fraturas experimentais dorádio de cães tratadas com plasma rico em plaquetas. ARS Veterinária, 27(1): 1-6, 2011.

Suaid, F.F.; Santamaria, M.P.; Carvalho, M.D.; Souza, H.W.; Sallum, E.A.; Nocitti Junior, F. H. Avaliação clínica da associação do plasma rico em plaquetas (PRP) com o enxerto de tecido conjuntivo subepitelial em retrações gengivais criadas em cães. Periodontia, 17(1): 68-75, 2007.

Torricelli, P.; Fini, M.; Filardo, G. Regenerative medicine for the treatment of musculoskeletal overuse injuries in competition horses. International Orthopaedics, 35(10): 15691576, 2011.

Vendramin, F.S.; Franco, D.; Nogueira, C.M.; Pereira, M.S.; Franco, T.R. Plasma rico em plaquetas e fatores de crescimento: técnica de preparo e utilização em cirurgia plástica. Revista do Colégio Brasileiro de Cirurgiões, 33(1): 24-28, 2006.

Vendramin, F.S.; Franco, D.; Schamall, R.F.; Franco, T.R. Utilização do plasma rico em plaquetas (PRP) autólogo em enxertos cutâneos em coelhos. Revista Brasileira de Cirurgia Plástica, 25(1): 4-10, 2010.

Vendruscolo, C.P.; Carvalho, A.M.; Moraes, L. F.; Maia, L.; Queiroz, D.L.; Watanabe, M.J.; Yamada, A.L.M.; Alves, A.L.G. Avaliação da eficácia de diferentes protocolos de preparo do Plasma Rico em Plaquetas para uso em Medicina Equina. Pesquisa Veterinária Brasileira, 32(2): 106-110, 2012. 
Whitlow, J.; Shackelford, A.G.; Sievert, A.N.; Sistino, J.J. Barriers to the acceptance and use of autologous platelet gel. Perfusion, 23: 283-289, 2008.

Yamada, A.L.M.; Carvalho, A.M.; Oliveira, P.G. G.; Felisbino, S.L.; Queiroz, D.L.; Watanabe, M.J.; Hussni, C.A.; Alves, A.L.G. Plasma rico em plaquetas no tratamento de lesões condrais articulares induzidas experimentalmente em equinos: avaliação clínica, macroscópica, histológica e histoquímica. Arquivo Brasileiro de Medicina Veterinária e Zootecnia, 64(2): 323-332, 2012. 